feed drive load measurement, heavy turning, force sensors

Pawel MEDYK ${ }^{1 *}$

Marcin KASPRZAK ${ }^{1}$

\title{
APPROACH TO FEED DRIVE LOAD MEASUREMENTS IN HEAVY TURNING
}

\begin{abstract}
It is well known that the forces loading the feed axes carry a lot of information about the machining process. The measurement of the forces opens the possibility of implementing such functions as cutting tool condition diagnosis, tool breakage detection and adaptive feed control aimed at maintaining constant loading. Hence inexpensive, but usable in industrial conditions, force sensors are sought for the steerable axes. The article describes a feed drive load measuring system based on industrial force sensors. These are strain gauge sensors located in the ball screw area. The system was designed for compressive and tensile forces of up to $30 \mathrm{kN}$. The effect of nonaxial forces on the measurement error is examined. The proposed system does not introduce any new elements into the machine structure and requires only its minor modifications. The system was tested in a strength testing machine.
\end{abstract}

\section{INTRODUCTION}

In the development of cutting machine tools much attention is devoted to the monitoring of the cutting force as the input parameter for evaluating and compensating workpiece dimensional and geometrical errors. The monitoring of machine tool operational properties and machining process correctness for a long time has been the subject of numerous studies and many reports from the studies have been published. Sensorics, as applied to the measurement of spindle bearing loads, axial displacement and wear and spindle assembly dynamics in order to counteract chatter, has been particularly intensively studied.

The integration of measuring devices into spindle assemblies received much space in [1]. Worth noting is the paper by Chen J.S. [2], analysing the behaviour of high-speed and high-load electrospindle bearing units for different preloads and different machining conditions. Jedrzejewski and Kwasny studied the behaviour of bearing units and their proposed approach to the intelligent diagnosis and supervision of all the main drives of machine tools deserves special attention [3]. Another work worth noting is the above authors' paper dealing with milling machine diagnosis based on limit values of such quantities as circumferential backlash in drive system parts, clearances in drive units and

\footnotetext{
${ }^{1}$ Department of Machine Tools and Mechanical Technologies, Wroclaw University of Science and Technology, Poland E-mail:pawel.medyk@pwr.edu.pl https://doi.org/10.36897/jme/128169
} 
temperatures in spindle bearings [4]. Brecher C. and Hirisch took up the subject of the diagnosis and compensation of machine tool thermal errors due to changes in ambient temperature [5]. The monitoring of the operational properties of machine tools received much attention in paper [6] by Roy R. at al., dealing with continuous maintenance with a special focus on the application of smart sensors to monitor machine tool dynamic properties, positioning, energy consumption, self-healing and self-repair. From among the studies on the monitoring of the dynamic properties of ball screw drives one should mention paper [7] by Verl A. who examined the effect of the feed rate on the change in load inside a ball screw, and paper [8] by Jedrzejewski at al. in which the effect of a moving heat source in the form of a ball screw nut on the accuracy of positioning the lathe carriage tool head (TCP) was examined.

For many years researchers have been interested in cutting process and tool point wear monitoring, which is the subject of paper [9] by Jemielniak K. and Kosmol J., devoted to the monitoring of tool condition, wear and chipping and disturbances in dynamic machining processes. The requirements which monitoring systems must meet, the complexity of such systems and directions in their development, especially as concerns the performance of the sensors used in CNC machine tools, are discussed in, e.g., paper [10] by Skoczynski et al. The complexity of the compensation of errors in the steerable axes, especially real-time compensation based on signals acquired from a monitoring system, is the subject of paper [11] by Medyk et. al. A major approach to the contemporary automation of manufacturing is to treat machining machines as mechatronic systems shaped by integrating physical modules and virtual modules into cyber physical modules forming the basis for the active and smart control of efficiency and accuracy. Such an approach was presented by Monostori L. et. al. [12].

The present research deals with the design of a system for measuring forces loading the tool carriage of a lathe for regeneration of the wheelsets of rail-vehicles. Based on other tests of this machine, the need to measure the cutting force components parallel to the $X$ and $\mathrm{Z}$ axes of the machine tool reference system was determined. The requirements for the measuring system was that it should fit into the compact tool carriage offering little space for mounting sensors, it should consider the wide range of the forces that appear during turning of the wheelset rims and it should be possibly high sensitive. Because of the little space available for installation and the high price of commercial measuring systems the latter were not considered.

The aim of the research was to create a system that fulfil those requirements and to thoroughly test the performance of this instrument in the target operating conditions. Sensors were to be selected based on an analysis of the measuring properties and dimensions of the available force sensors and the requirements stemming from operation in industrial conditions in integration with the CNC system. Then the sensors were to be subjected to detail tests. For this purpose, considering the developed monitoring strategy, a proper signal processing system had to be built and equipped with software. Strain gauge sensors of appropriate size, with the required force measuring range were selected.

In future research, measurement of the given components of the cutting force will be used for machining process control ensuring the minimization of machining errors and the possibility of their active compensation. 


\section{SELECTION OF FORCE MEASURING SYSTEM COMPONENTS}

The first stage of creating the measurement system was to select appropriate sensors. To meet the requirement that the system is meant to be an integral part of the machine, industrial components were used - built for harsh environmental conditions, with proven performance and interchangeable. This excluded the use of popular strain gauge-based systems [15] measuring process parameters via a holder of special design. In the target operating conditions, the measuring instruments were to be seated in the carriage atypical in its design, offering little space for building them in, whereby no expensive, ready-made cutting force measuring systems could be used. A major difficulty in selecting a suitable sensor was to satisfy the requirements concerning its measuring range, small size and relatively low price.

From among the commercially available products ring force sensors CL20-8 made by ZEPWN (Fig. 1) were chosen.

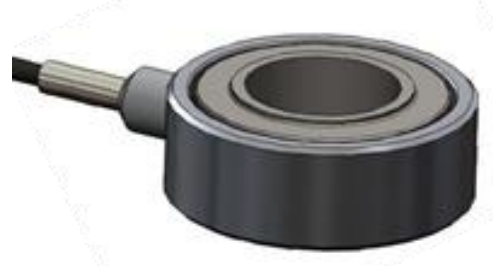

Fig. 1. Ring force sensor

Such sensors are produced in two versions: one based on tensometric components and the other one on piezoelectric components. Considering the total cost of the measuring circuit, sensors based on tensometric components were chosen. The sensors have a wide measuring range (up to $25 \mathrm{kN}$ ) and small dimensions, can measure both compressive and tensile forces, can be quickly and easily installed in the machine and their output signal is supported by the standard inputs of many control systems. Hence this type of sensor meets the requirements set by the design. The drawbacks of such sensors are processing characteristic nonlinearity (below 5\%) and the influence of nonaxial forces and temperature on the measurement. For the sensor to function properly it must be preloaded by means of a screw. An interesting solution is screw stress measurement by a built-in fibre-optic Bragg sensor [16]. This could make possible transmission of force on the same principle as in the designed system, but without the use of ring sensors. Unfortunately, the disadvantage of this solution is the force transmission area which is larger than the screw connection area.

The aim of the project was to fully integrate the system with the lathe. Therefore, the sensors and the measuring circuits had to be built into the machine. In order to determine the target system parameters and to develop the proposed solution an external measuring system was created and subjected to testing. The system had extensive data processing capabilities and was highly flexible as regards the number and kind of measured quantities. This made it possible to determine the most suitable cutting force measuring system solution for the machine. The diagram of the monitoring system is shown in Fig. 2. 


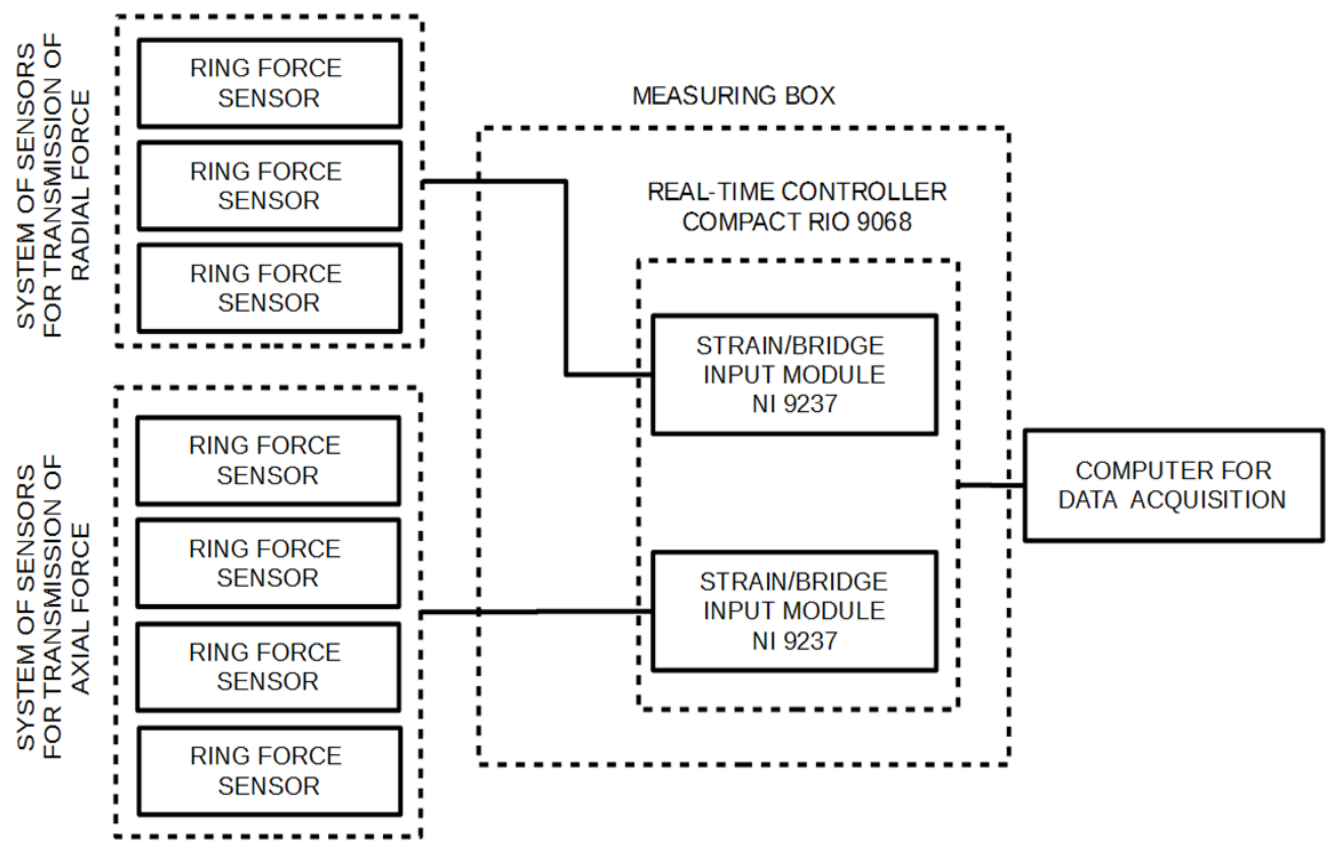

Fig. 2. Diagram of monitoring system

The system's main component was a real-time controller Compact Rio 9068 with National Instruments strain measurement cards. The controller was connected with a data processing and recording computer. This system enabled the simple hook up of sensors and data acquisition with a frequency of up to $50 \mathrm{kHz}$ and a resolution of 24 Bit. Besides force sensors, displacement sensors and temperature sensors could be connected to the system. The signals from the sensors were used to verify the design solution. After the system had been verified and the operating parameters determined, the above measuring circuit components were replaced with the appropriate inputs of the machine control system.

\section{LOCATION OF MONITORING SYSTEM SENSORS}

The task of the monitoring system was to measure cutting forces in two steerable machine axes. Because of the limited space, the difficult machining conditions and the complexity of the systems direct measurements (used mostly only in laboratory conditions) were ruled out. On the other hand, the data easily acquirable from the $\mathrm{CNC}$ system, i.e. power and motor holding torque, determined from the motor current flow are laden with many errors stemming from, for example, temperature influence, sensitivity to friction influence, power increased to keep torque constant and differences due to machine runtime [17]. Therefore, it was decided to locate the sensors in the area of the ball screws performing motion in the directions parallel to the reference axes of the machine tool: $X$ and $Z$. This approach can be understood as a measurement of cutting force components described as $F_{X m}$ and $F_{Z m}$ in ISO standard [19]. The load of the ball screw performing motion along direction $Z$ is measured by four strain gauges located between the ball screw's bearing 
housing and the structural element of the carriage. The load along direction $X$ is measured by three strain gauges located between the housing of the ball screw rear bearing and the structural element of the slide. The two locations are shown in Fig. 3.

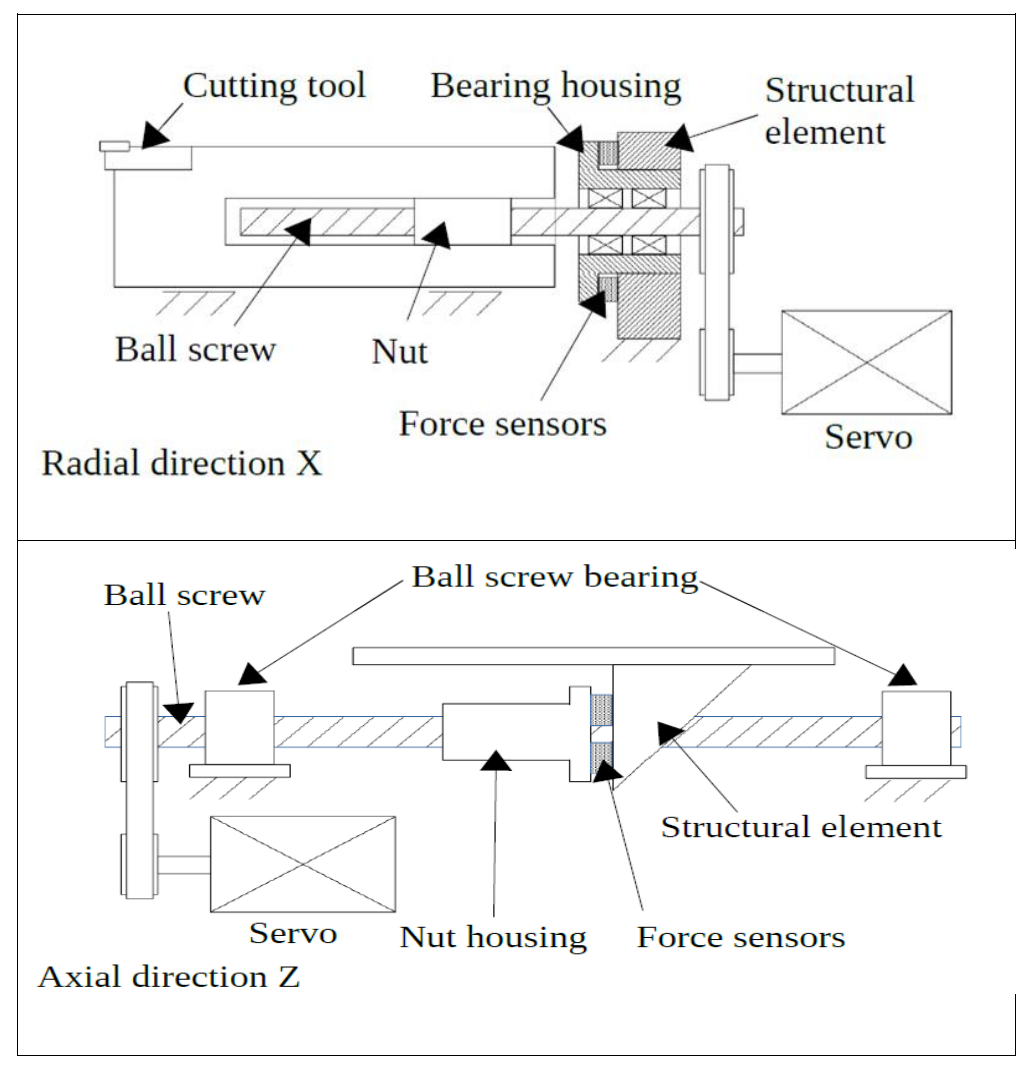

Fig. 3. Location of sensors in machine

The installation of the sensors in the specified places necessitated small modifications in the machine tool structure. The ball screw housing (more precisely its connection with the structural element) was modified in order to accommodate the system measuring the load along direction $X$. The fixed welded connection was replaced with a sliding connection. The two structural components were joined by means of three bolts with ring force sensors placed under their heads. In order to implement load measurement along direction $Z$ only the nut housing was modified. Its connection with the structural element by means of two bolts M16 was replaced with a connection by means of four bolts M8 with sensors. Sensors of the same type were used to measure forces along the two axes.

\section{TRIAL SYSTEMS FOR VERIFYING CUTTING FORCE TRANSMISSION SOLUTIONS}

Before the target system to be permanently installed in the machine body was made, trial systems had been created. Their aim had been to verify force transmission in 
the assumed operating range characteristic of the machine for the regeneration of wheelsets. The main structural parts, such as the bearing housing and the nut housing, were modelled on the target machine using the same type of material. Also, the force application point was the same as in the target machine.

The two systems could be loaded with compressive forces of up to $30 \mathrm{kN}$, deviating maximally $5^{\circ}$ from the axis. In addition, the system for measuring the machine axial forces (direction $Z$ ) could bear tensile forces of up to $30 \mathrm{kN}$. The two solutions are presented in Fig. 4.

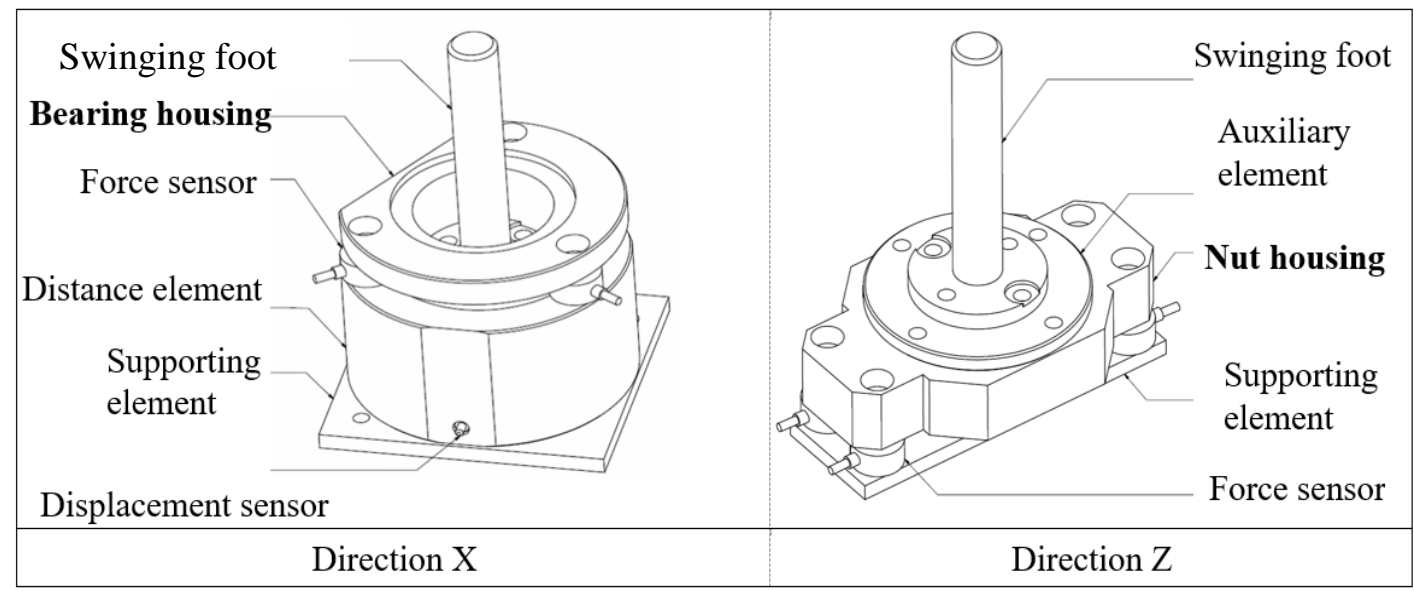

Fig. 4. Models of systems for transmission of cutting force components parallel to axes $X$ and $Z$

Also eddy-current displacement sensors Micro-Epsilon eddyNCDT 3010 with a measuring range of $1 \mathrm{~mm}$ and a resolution of $0.02 \mu \mathrm{m}$ had been included in the $X$ component of the cutting force measuring system, whereby it became possible to test the system displacement along the direction perpendicular to the load.

This displacement could be the cause of the faulty operation of the sliding connection in the target system. In both cases, the pressure exerting element was a swinging foot, which could deviate a few degrees from the axis when carrying load.

In the $X$ component of the cutting force measuring system, the force application point was in the area where the bearings were fixed, while in the other system it was in the place where the nut is attached. The force in the target machine was to be carried by these areas. Allen screws M8 (property class 12.9) had been used to mount the sensors and apply the preload.

\section{TESTING OF SYSTEMS IN STRENGTH TESTING MACHINE}

The systems for measuring respectively $X$ and $\mathrm{Z}$ components of cutting force were installed and tested in a strength testing machine Zwick/Roell 1478 with an operating range of up to $100 \mathrm{kN}$. The machine had been calibrated prior to the tests. The complete test stand is shown in Fig. 5. 


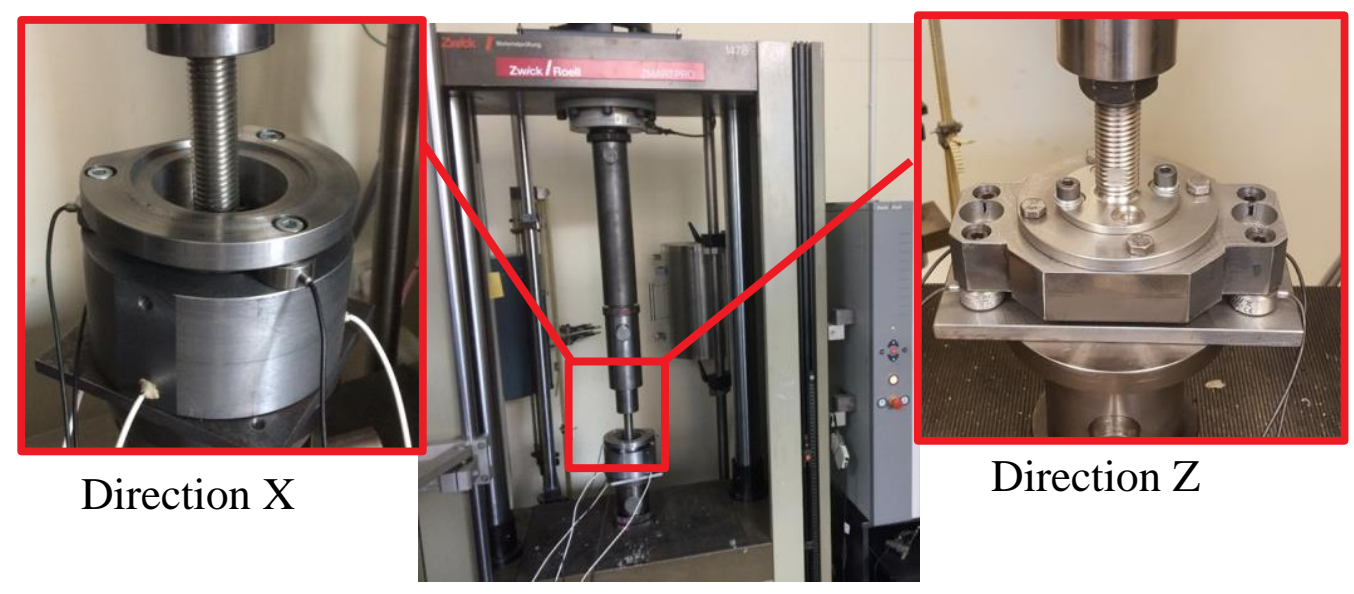

Fig. 5. View of systems installed in strength testing machine

\subsection{TESTING THE FORCE TRANSMISSION SYSTEM FOR THE $X$ COMPONENT OF THE CUTTING FORCE}

The primary aim of testing the $X$ component of the cutting force transmission system was to check the response of the set of sensors to the application of compressive loads of $0-30 \mathrm{kN}$. Moreover, the system was subjected to the action on nonaxial forces in order to determine the influence of nonlinearity on the measured quantity, and the deflections which could make the correct operation of the sliding connection impossible. Some of the test assumptions was based on the results of preliminary tests carried out on a single sensor. The results of the tests had shown the sensor's high nonaxial force and torsional moment compliance. Furthermore, depending on the inclination of the forces, the error value had been positive or negative. This had indicated potential difficulties in achieving results repeatability in the target solution. The sensor had also been checked for stiffness and the influence of temperature on measurement. Under the load of $15 \mathrm{kN}$ the sensor had deflected by about $16 \mu \mathrm{m}$ and as a result of the temperature difference of $1^{\circ} \mathrm{C}$ the measured quantity changed by about $30 \mathrm{~N}$.

The tested $X$ component of the cutting force transmission system is based on three force sensors spaced at every $120^{\circ} \mathrm{C}$ on a circle. In addition, it is equipped with three sensors measuring the displacement of the lower part of the sleeve along the direction perpendicular to the axis. The sensors are spaced at every $120^{\circ}$ on a circle but are shifted by $60^{\circ}$ relative to the force sensors (Fig. 6).

The shift of the displacement sensors by $60^{\circ}$ relative to the force was based on predictions about the direction of the system's deflection. It was assumed that the direction would coincide with the asymmetry of the bearing sleeve, whereby one of the sensors would indicate a value close the sleeve's maximum displacement. Fig. 6 also shows the directions of the action of the forces and the direction along which sleeve shift is measured. The system's cross section shows the force application point, which is located on the inner step of the sleeve. In this place in the target system there is the ball screw bearing via which the load is transmitted. The sliding connection between the sleeve's outer surface and the structural element in the machine was replaced in this system with free space allowing 
the sleeve to move freely. Consequently, potential imperfections of this connection were eliminated, whereby we could focus on the properties of the transmission of forces by the set of sensors. At the same time, knowing the range of motion of the sleeve along this direction we could approximately determine the operating ability of the sliding connection.

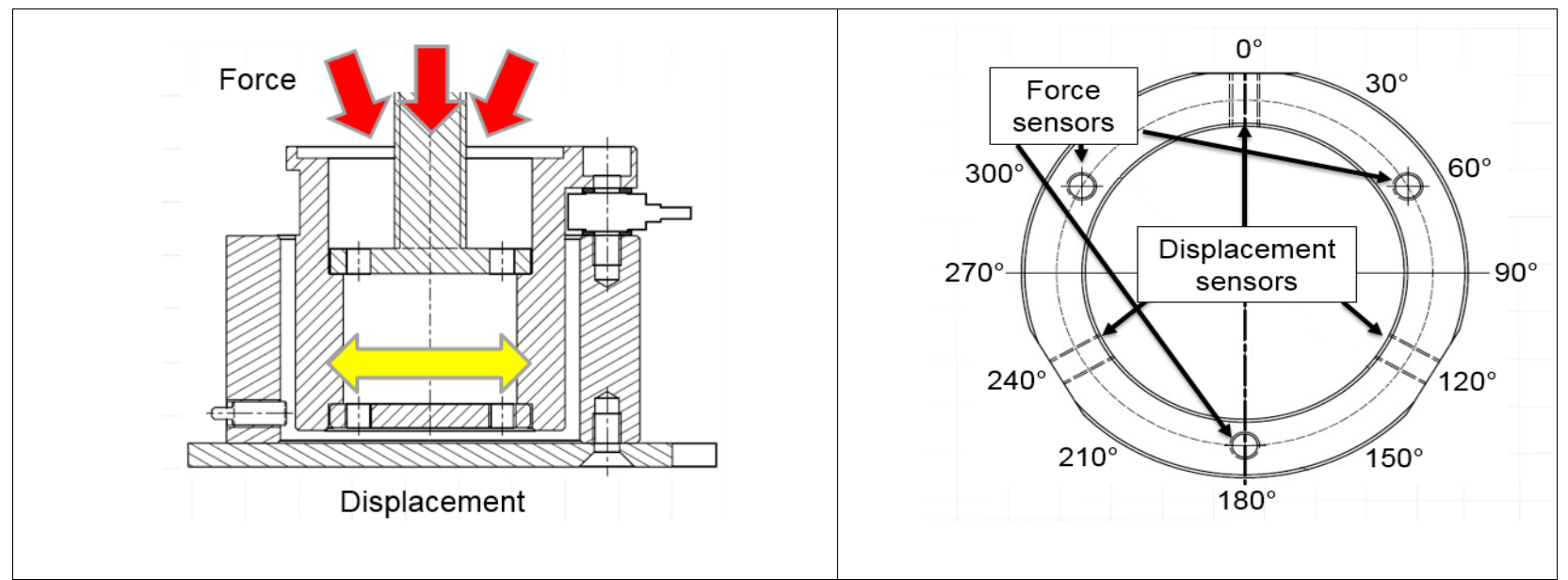

Fig. 6. Cross-sectional view of X component of the cutting force measurement system, and arrangement of sensors

The testing of the measuring system began with tests of its ability to measure axial load increasing over time. The tests were carried out for three ranges: $0-10 \mathrm{kN}, 0-20 \mathrm{kN}$ and $0-30 \mathrm{kN}$. During loading by means of the strength testing machine data were acquired from the force and displacement sensors. The force sensors were preloaded with the force of $10 \mathrm{kN}$. The results are presented in Fig. 7.

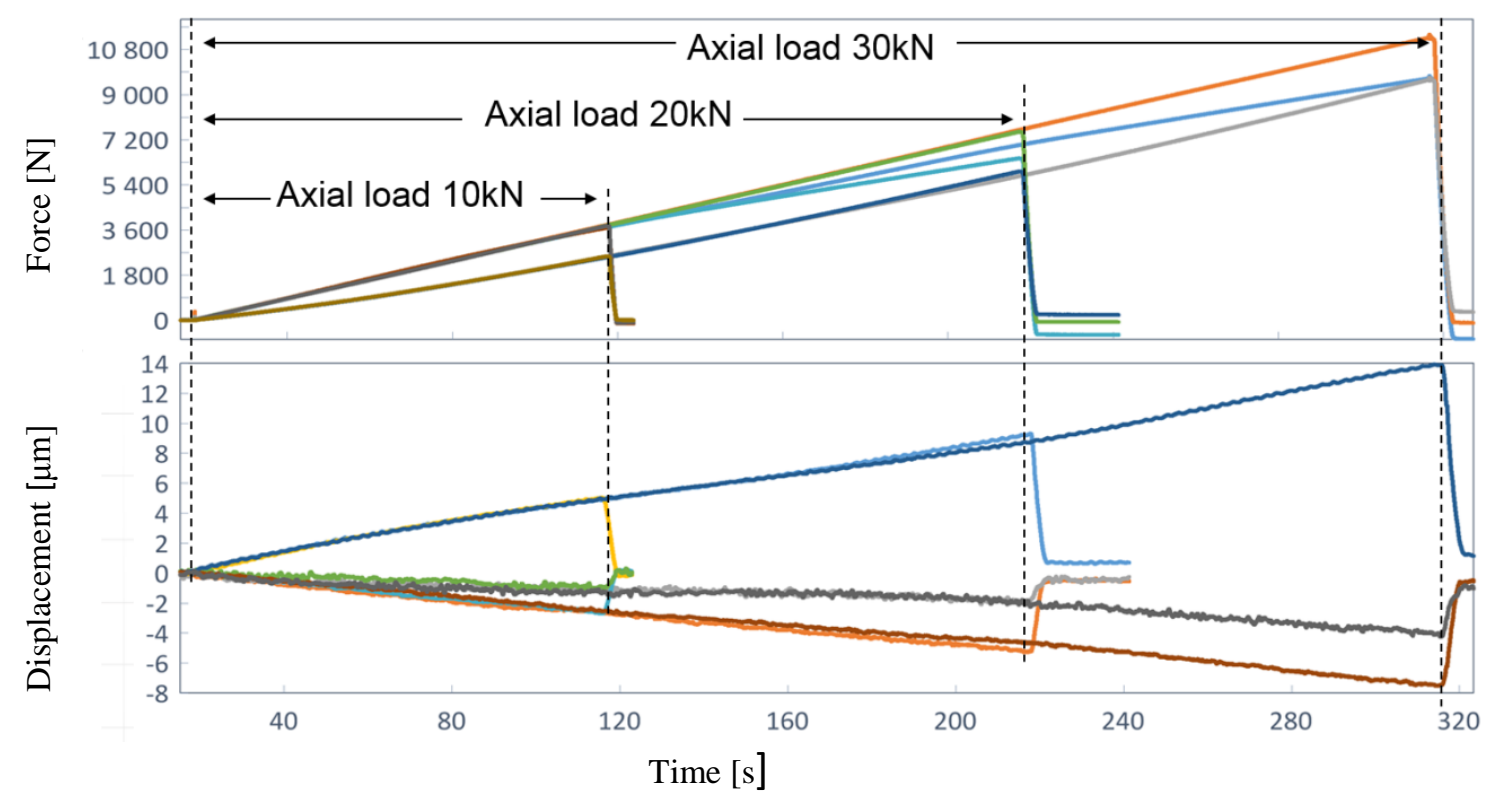

Fig. 7. System for measuring X component of the cutting force - signals from force and displacement sensors 
It appears from the diagrams in Fig. 7 that the system's behaviour is repeatable and linear in the test range. During the experiments, no drift was observed, only a slight measurement noise and occasional coarse errors are visible. One can notice in Fig. 7 differences between the measured force and displacement values and the reference ones, which are strongly visible in the final phase of loading with the force of $20 \mathrm{kN}$ and during unloading to 0 . This behaviour of the system was caused by the loosening of the bolted connection. The problem was solved using an adhesive for bolted connections. It appears from the displacement diagrams that the system bends in the same direction in a repeatable manner. The results did not change after the experiment was repeated several times for the measuring system turned around its axis in the strength testing machine, whereby the suspicion that the machine imposed the direction of system bending was eliminated. One of the sensors indicates a considerably higher displacement value than the other sensors, which confirms the assumption about bending consistent with the direction of system compliance due to the asymmetry of the sleeve. After system unloading a slight displacement of the sleeve and no return to the initial value are visible. The direction of this displacement can be linked to the values indicated by the force sensors. This is confirmed by the previously indicated loosening of the bolted connection and therefore one can conclude that the error was not connected with force measurement. The maximum system displacement under the axial force of $30 \mathrm{kN}$ amounted to $14 \mu \mathrm{m}$.

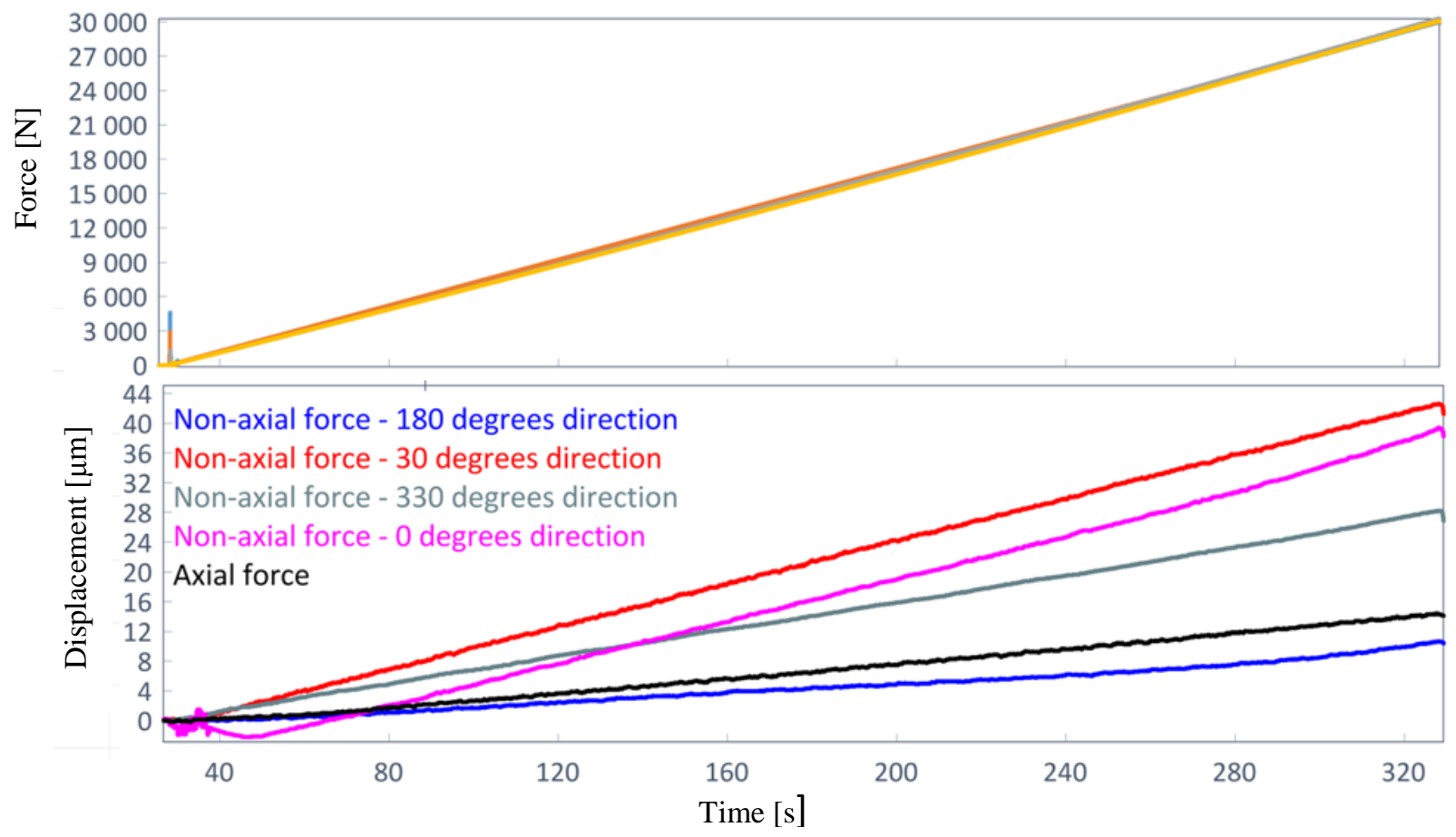

Fig. 8. System for measuring X component of the cutting force - action of axial and nonaxial forces, comparison

The next stage in the investigations consisted in carrying out measurements as the system was being loaded with a force linearly increasing over time up to the value of $30 \mathrm{kN}$, whose direction deviated from the measuring system axis. The tests were carried out for 
the load deviating $4^{\circ}$ from the system axis in four different directions. The action of nonaxial forces was investigated for the arrangement of the sensors shown in Fig. 6 and the sleeve mounted with its flat side up. The direction of the forces deviated consistently with the graduation marked in the figure towards $0^{\circ}, 30^{\circ}, 180^{\circ}$ and $330^{\circ}$. The test results are presented in Fig. 8.

The top diagram in Fig. 8 shows a comparison of the sums of the forces measured by the sensors for the action of respectively axial forces and nonaxial forces and the strength testing machine reference value. The diagrams coincide with each other and the maximum difference between them amounts to $581 \mathrm{~N}$. The mean relative error remains at the level of about $3-4 \%$ for both system loading with the axial force and with forces deviating from the system axis (Table 1).

Table 1. Tests of $\mathrm{X}$ component of the cutting force measuring system - mean and maximum errors

\begin{tabular}{|l|c|c|c|}
\hline Direction of force action & $\begin{array}{c}\text { Maximum absolute error } \\
\max _{i \in\{1, \ldots, N\}}\left|x_{i}-t_{i}\right|\end{array}$ & $\begin{array}{c}\text { Mean absolute error } \\
N\end{array}$ & $\begin{array}{c}\text { Mean relative error } \\
N\end{array} \sum_{i=1}^{N}\left|x_{i}-t_{i}\right| \frac{1}{N} \sum_{i=1} \mid t_{i} * 100 \%$ \\
\hline $\begin{array}{l}\text { Deviation of } 4^{\circ} \text { from measuring } \\
\text { system axis towards } 30^{\circ} \text { (Fig. 6) }\end{array}$ & $581 \mathrm{~N}$ & $370 \mathrm{~N}$ & $4.10 \%$ \\
\hline $\begin{array}{l}\text { Deviation of } 4^{\circ} \text { from measuring } \\
\text { system axis towards } 180^{\circ} \text { (Fig. 6) }\end{array}$ & $444 \mathrm{~N}$ & $303 \mathrm{~N}$ & $3.58 \%$ \\
\hline $\begin{array}{l}\text { Deviation of } 4^{\circ} \text { from measuring } \\
\text { system axis towards } 330^{\circ} \text { (Fig. 6) }\end{array}$ & $415 \mathrm{~N}$ & $220 \mathrm{~N}$ & $3.00 \%$ \\
\hline $\begin{array}{l}\text { Along measuring system axis, } \\
\text { compressive force }\end{array}$ & $498 \mathrm{~N}$ & $331 \mathrm{~N}$ & $3.78 \%$ \\
\hline
\end{tabular}

where: $t_{i}$ - the reference value for the $\mathrm{i}$-th measurement of the force (the measurement comes from the strength measuring machine),

$x_{i}$ - the force value for the $\mathrm{i}$-th measurement by the tested measuring system,

$N$ - the number of measurements taken during the experiment.

Therefore, one can say that the system sufficiently well maps the actual value of the force and is not susceptible to nonaxial forces with a deviation of $4^{\circ}$. One can also notice that, as expected, force nonaxiality has a major effect on the sleeve displacement value. A change in the direction of sleeve displacement, consistent with that of the loading force, was observed during testing. When the force was applied along the direction of system compliance, the deflection and the one produced under the axial force would add up, as one can see for the load inclination towards $0^{\circ}$ (Fig. 8). In the opposite direction, i.e. towards $180^{\circ}$, the force would counteract system compliance, whereby a smaller displacement than for the axial force was obtained. It also appears from the diagram that the force directed towards $0^{\circ}$ did not result in the largest displacement of the system. Based on the behaviour of the sleeve during axial loading (Fig. 7) one can determine the direction of system compliance. Judging by the difference between the values measured by the two sensors indicating smaller displacements one can say that system compliance is not exactly directed towards $0^{\circ}$, but shifted to the right relative to this direction. Hence the driving force directed 
towards $30^{\circ} \mathrm{C}$ caused a larger displacement of the sleeve. The maximum displacement of the sleeve amounted to $42 \mu \mathrm{m}$. It should be noted that the measuring system's characteristic changed only slightly as the system was being loaded with a nonaxial force in different directions. From the similarity of the error plots for the measurements of forces acting in different directions (Fig. 9) one can conclude that the larger part of the system measurement error stems directly from the nonlinear characteristic of the strain gauges.

\subsection{TESTING THE FORCE TRANSMISSION SYSTEM FOR THE $Z$ COMPONENT OF THE CUTTING FORCE}

The $Z$ component of the cutting force transmission system was tested, similarly as the $X$-component force transmission system, to check the response of the set of sensors to the action of axial and nonaxial forces compressive within the range of 0-30 kN. Since it was not necessary to change the connection technology in order to integrate the axial force measuring system into the machine, no displacement was measured. But considering the character of the operation of this system, its response to the action of tensile axial forces ranging from 0 to $30 \mathrm{kN}$ was tested. The cross section of the system and the arrangement of the sensors are shown in Fig. 10.

The main component in this solution is the ball screw nut housing, which is fixed to the structural element by means of four bolts with force sensors. The number and size of the fixing bolts is the only change introduced into the previous machine structure. The use of the previous solution would require fixing the nut housing to the structure by means of two M16 bolts. The change to four M8 bolts was made based on tests carried out on the system with two larger ring force sensors placed under the heads of the M16 bolts. The test results had indicated a large error in force transmission and the system's incapability to register forces below $1800 \mathrm{~N}$. The point of application of the driving force in the system coincides with the place where the ball screw nut is secured to the housing, which is consistent with the anticipated way of force transmission in the machine.

Fig. 11 shows graphically the test results for loading the designed system with compressive and tensile axial forces in the ranges: $0-10 \mathrm{kN}, 0-20 \mathrm{kN}$ and $0-30 \mathrm{kN}$. The sensors were preloaded with a force of $10 \mathrm{kN}$. The bolts used for assembly were of property class 12.9 .

Based on the conclusions emerging from the testing of the previous system a bolted connection with the use of a thread locking adhesive was adopted in the current system. As a result, there is no connection loosening, whereby the values of the signals from the sensors return to the initial values after unloading. The system behaves in a repeatable and linear manner, even under the action of forces with the opposite sense. This is clearly seen in the top diagram in Fig. 12, in which the action of compressive and tensile axial forces is compared with the reference values obtained from the strength testing machine. As in the case of the measuring system for the $\mathrm{X}$ component of the cutting force, no drift was observed during the measurements, only a small measurement noise and a few coarse errors. The graphs coincide and the discrepancies between the measurements and the reference value amount to maximally $365 \mathrm{~N}$ for the compressive force and to $541 \mathrm{~N}$ for the tensile 
force. For forces (both compressive and tensile) greater than $2000 \mathrm{~N}$ the relative measurement error is much below 5\% (Fig. 13) and the mean relative error in the whole measuring range amounted to less than $1.5 \%$ (Table 2).
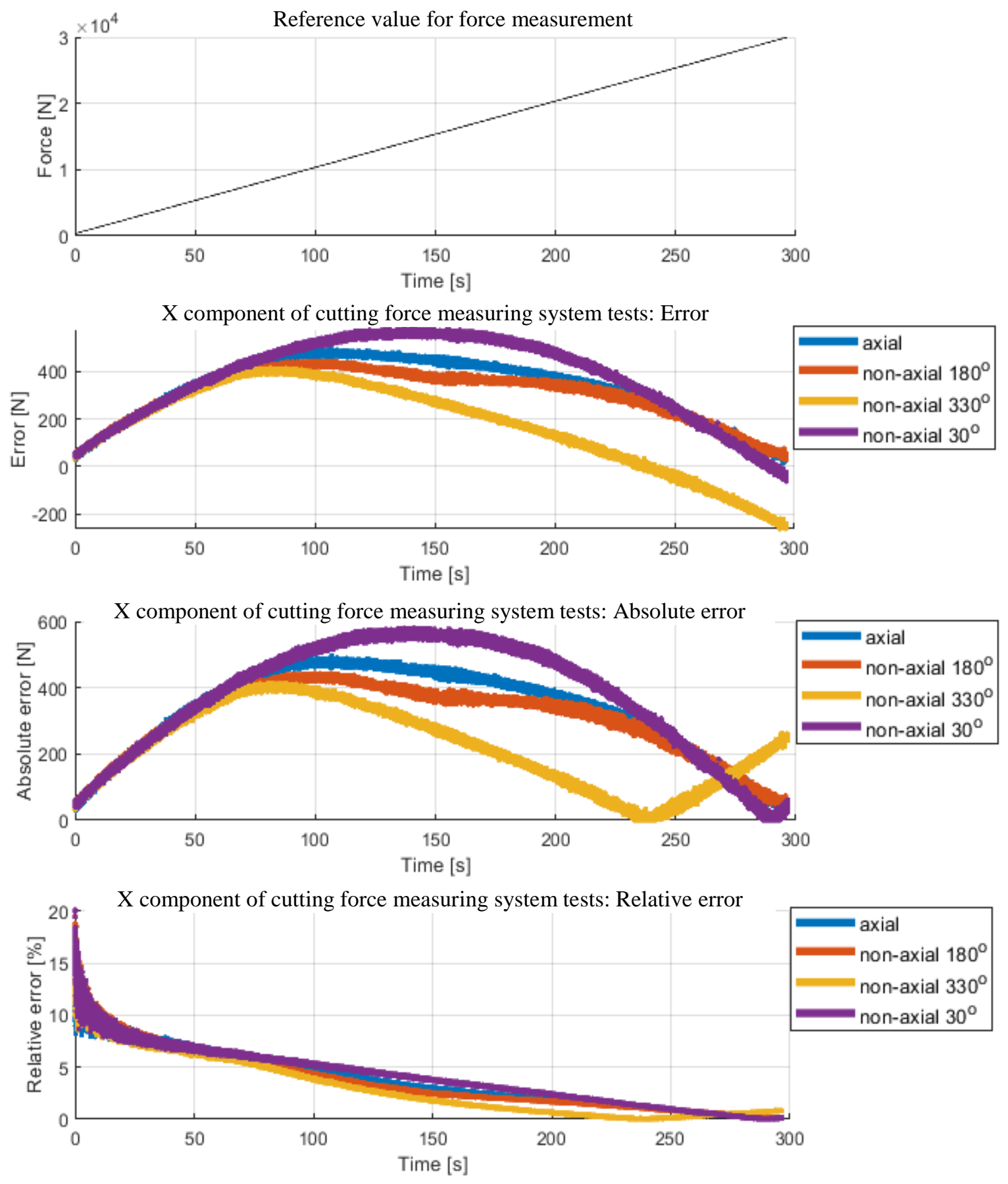

Fig. 9. Tests of $\mathrm{X}$ component of the cutting force transmission measuring system - measurement error plots

The bottom diagram in Fig. 12 presents the measurement results obtained by means of the tested measuring system for nonaxial forces with a deviation of $4^{\circ}$. The system was 
loaded in four different directions inclined towards $0^{\circ}, 90^{\circ}, 180^{\circ}$ and $270^{\circ}$ (Fig. 10). For comparison, the measurement results for the axial force and the strength testing machine reference value are included. As one can see, the divergence of results for the action of nonaxial forces is wider than for the action of the axial force (the top diagram in Fig. 12), amounting to as much as $1400 \mathrm{~N}$ for the force acting towards $90^{\circ}$. This observation is confirmed by the data contained in Table 2 and the error plots shown in Fig. 14.

The plots have different shapes and there are large differences in the mean absolute and relative error values between the axial force measurement and the nonaxial force measurement. During the tests the system showed greater compliance when forces deviating towards the shorter sides of the nut housing (towards $90^{\circ}$ and $270^{\circ}$ in Fig. 10) acted. Particularly high error values were noted when the system was loaded with the axial force deviating from the axis towards $90^{\circ}$ - the mean absolute error amounted to $1061 \mathrm{~N}$.

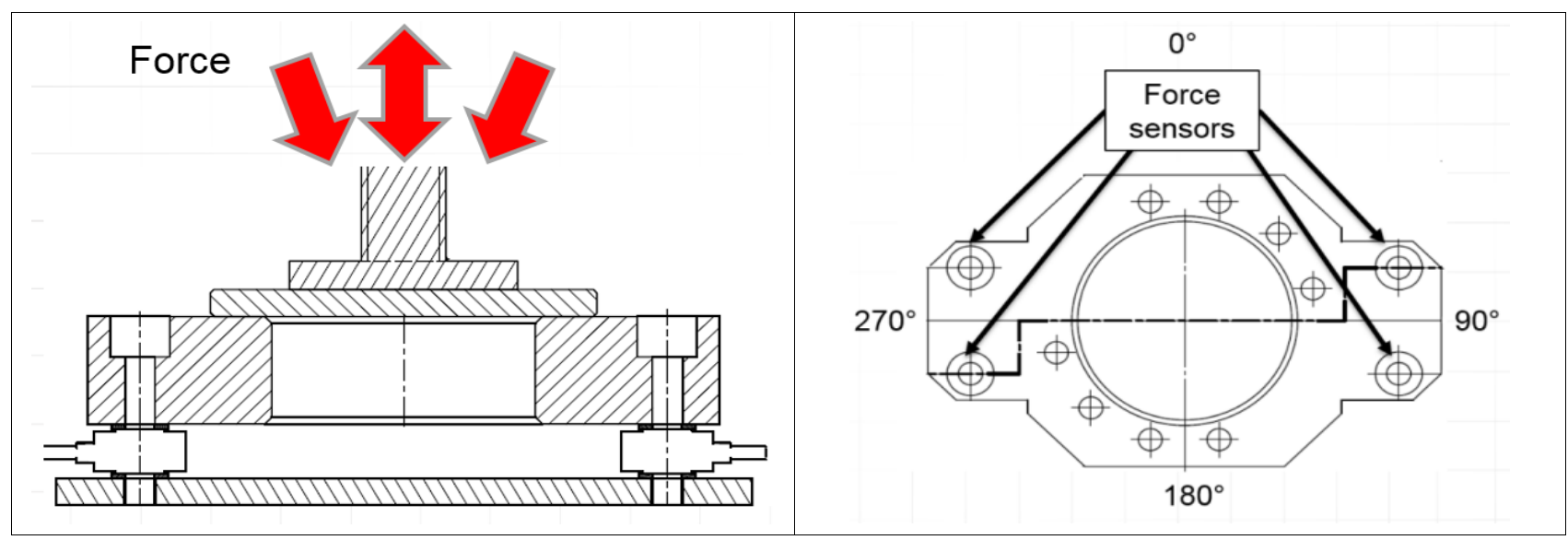

Fig. 10. Cross-sectional view of $\mathrm{Z}$ component of cutting force measuring system, and arrangement of sensors

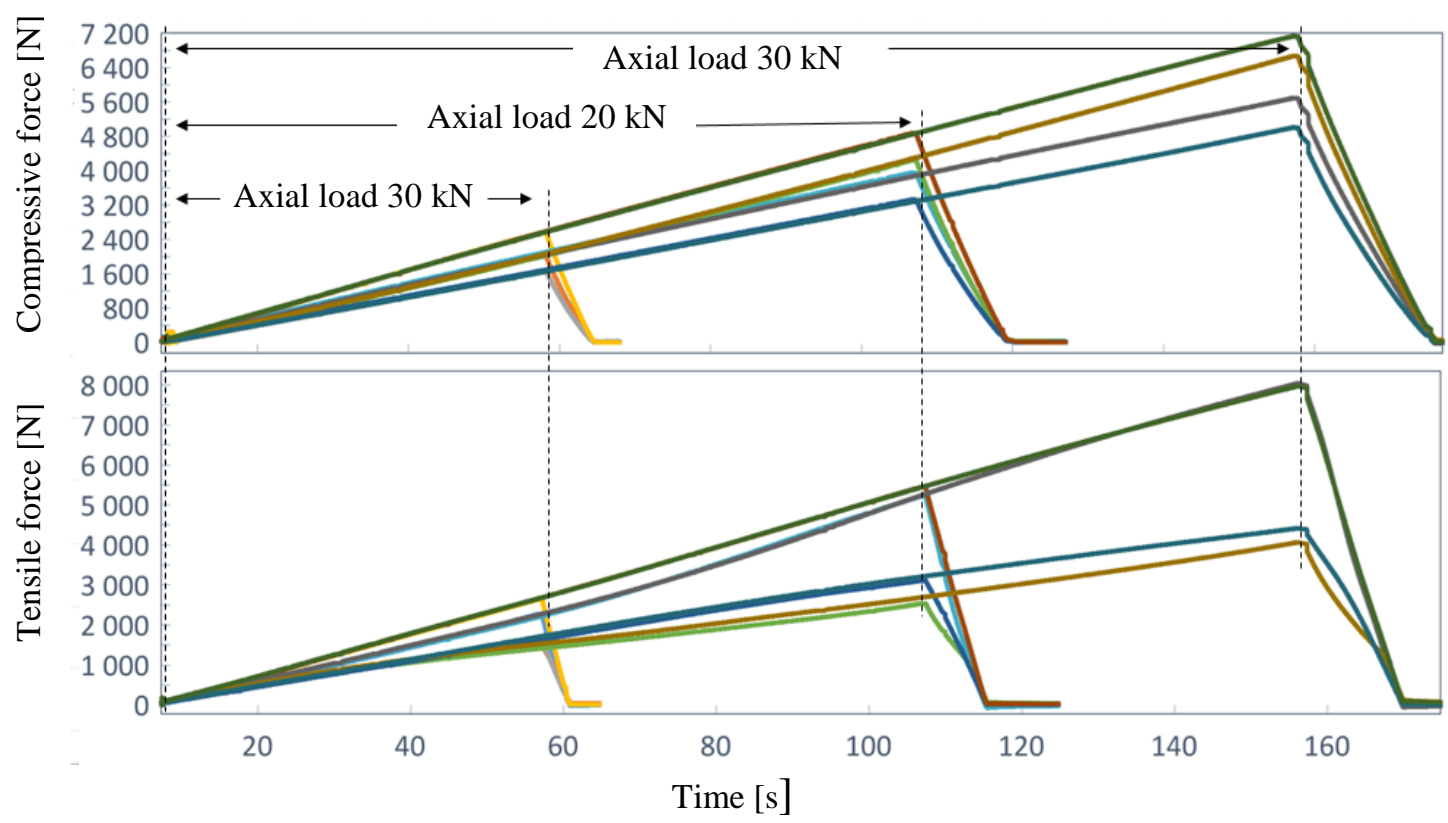

Fig. 11. Z component of cutting force measuring system's response to action of compressive and tensile forces 
Differences between the error characteristics are also visible for the measurements of nonaxial forces acting in different directions (Fig. 14). The differences in the shape of the graphs indicate that the main source of the measurement error is not the characteristic of the strain gauges, but most probably the imperfect workmanship of the system's mechanical parts. Nevertheless, the system behaves in a linear and repeatable manner. Up to the load of $7 \mathrm{kN}$ the graphs coincide, and the error remains at the level of $300 \mathrm{~N}$.

Table 2. Tests of $\mathrm{Z}$ component of cutting force transmission measuring system - mean and maximum errors

\begin{tabular}{|l|c|c|c|}
\hline Direction of force action & $\begin{array}{c}\text { Maximum absolute error } \\
\max _{i \in\{1, \ldots, N\}}\left|x_{i}-t_{i}\right|\end{array}$ & $\begin{array}{c}\text { Mean absolute error } \\
N \sum_{i=1}^{N} \mid x_{i}\end{array}$ & $\begin{array}{c}\text { Mean relative error } \\
N\end{array}$ \\
\hline $\begin{array}{l}\text { Deviation of } 4^{\circ} \text { from measuring } \\
\text { system axis towards } 0^{\circ} \text { (Fig. 10) }\end{array}$ & $630 \mathrm{~N}$ & $490 \mathrm{~N}$ & $4.81 \%$ \\
\hline $\begin{array}{l}\text { Deviation of } 4^{\circ} \text { from measuring } \\
\text { system axis towards } 90^{\circ} \text { (Fig. 10) }\end{array}$ & $1403 \mathrm{~N}$ & $1061 \mathrm{~N}$ & $8.14 \%$ \\
\hline $\begin{array}{l}\text { Deviation of } 4^{\circ} \text { from measuring } \\
\text { system axis towards } 180^{\circ} \text { (Fig. 10) }\end{array}$ & $813 \mathrm{~N}$ & $553 \mathrm{~N}$ & $4.99 \%$ \\
\hline $\begin{array}{l}\text { Deviation of } 4^{\circ} \text { from measuring } \\
\text { system axis towards } 270^{\circ} \text { (Fig. 10) }\end{array}$ & $670 \mathrm{~N}$ & $289 \mathrm{~N}$ & $4.34 \%$ \\
\hline $\begin{array}{l}\text { Along measuring system axis, } \\
\text { compressive force }\end{array}$ & $365 \mathrm{~N}$ & $163 \mathrm{~N}$ & $1.02 \%$ \\
\hline $\begin{array}{l}\text { Along measuring system axis, tensile } \\
\text { force }\end{array}$ & $541 \mathrm{~N}$ & $225 \mathrm{~N}$ & $1.46 \%$ \\
\hline
\end{tabular}

where: $t_{i}$ - the reference value for the i-th measurement of the force (the measurement comes from the strength measuring machine),

$x_{i}$ - the force value for the $\mathrm{i}$-th measurement by the tested measuring system, $N$ - the number of measurements taken during the experiment.

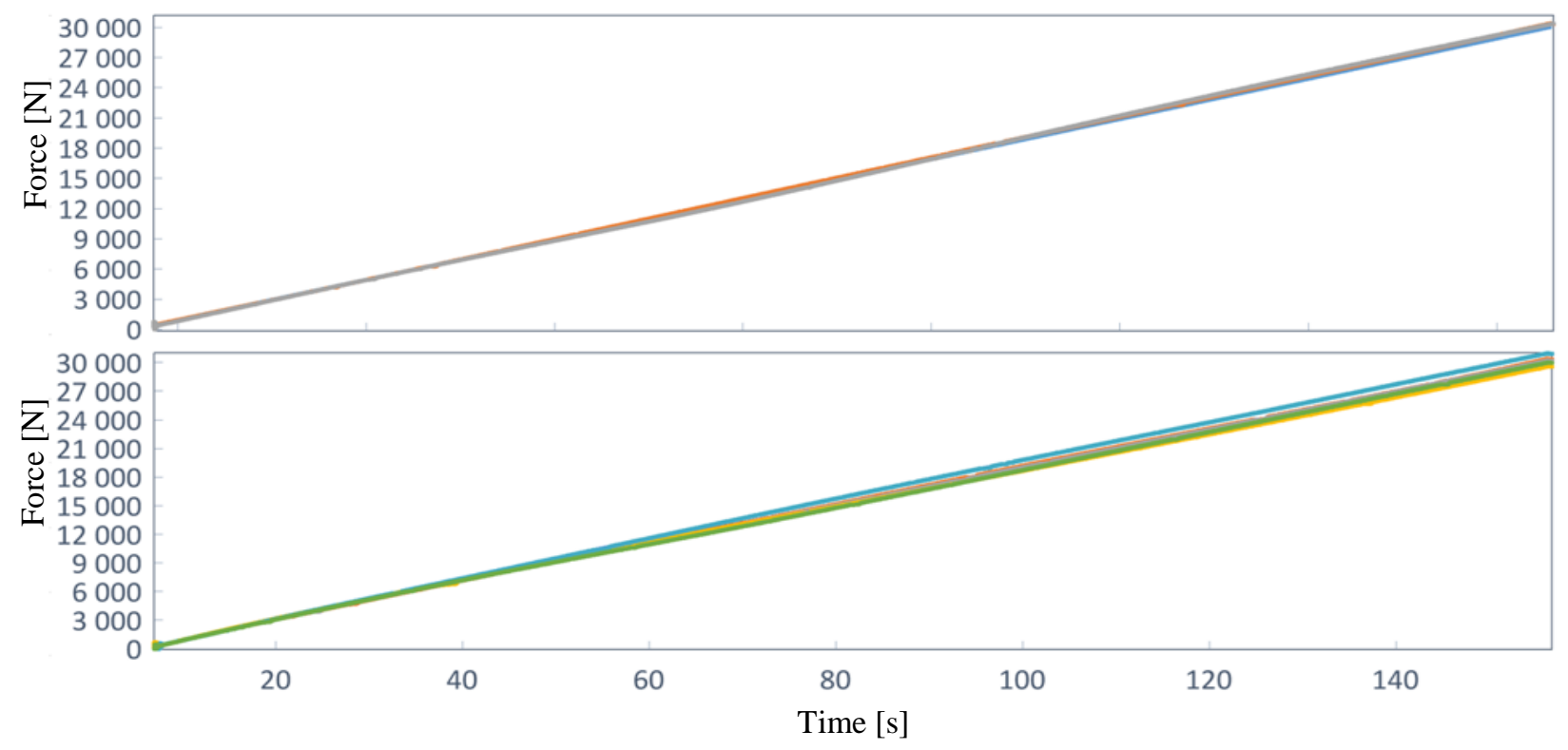

Fig. 12. Z component of cutting force measuring system - action of nonaxial forces and comparison of signals 

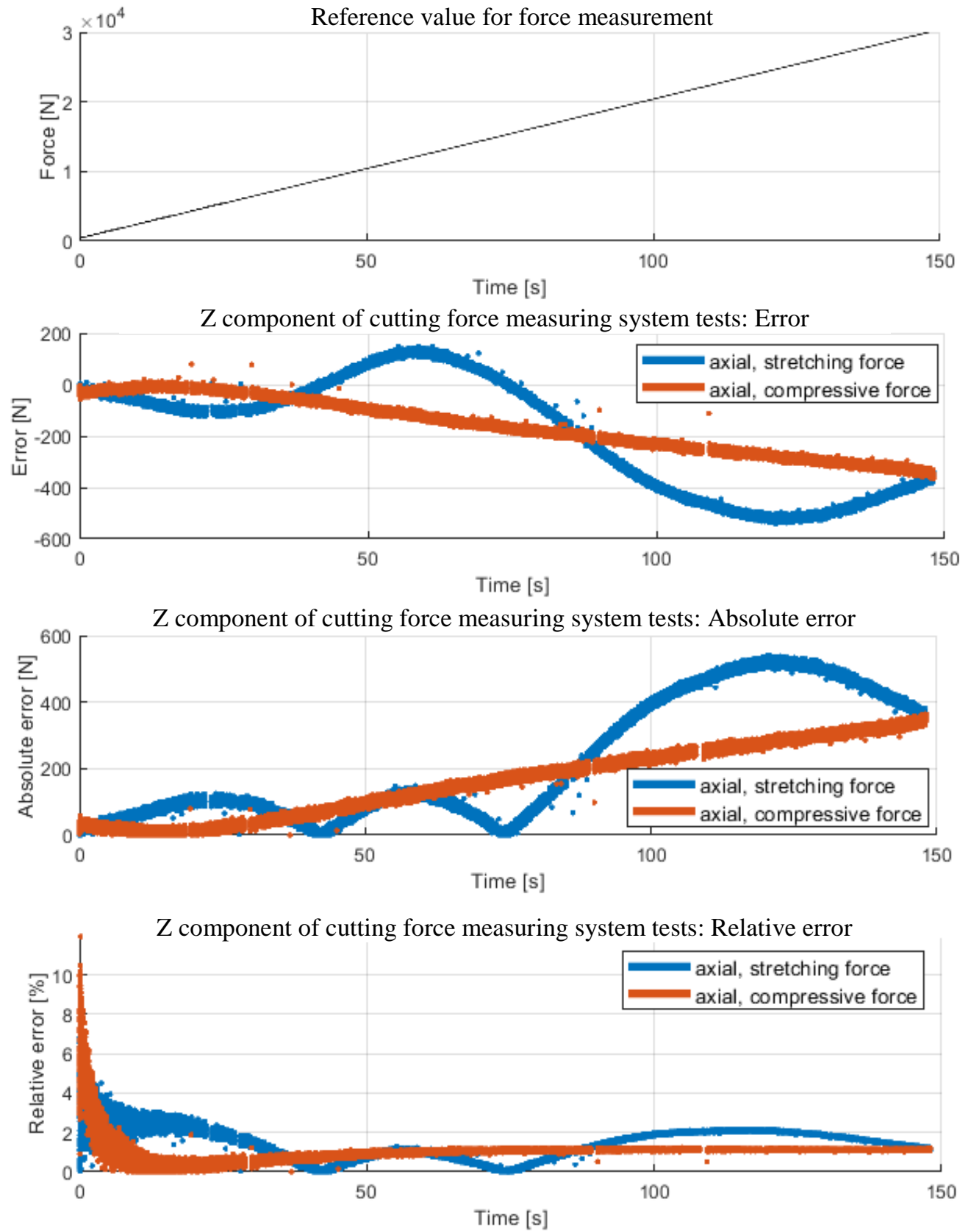

Fig. 13. Tests of $Z$ component of cutting force transmission measuring system - plots of measurement errors during loading with compressive and tensile axial forces

a)

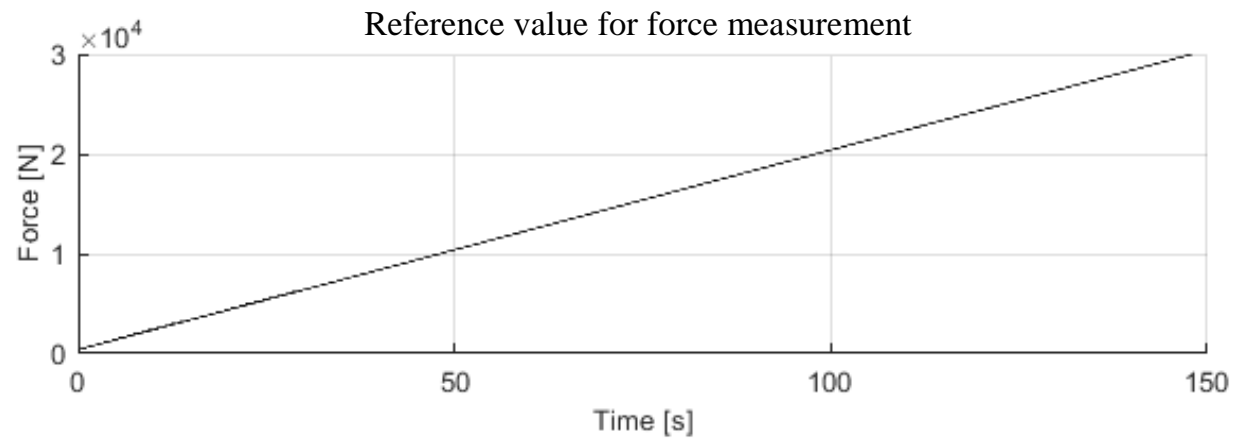


b)
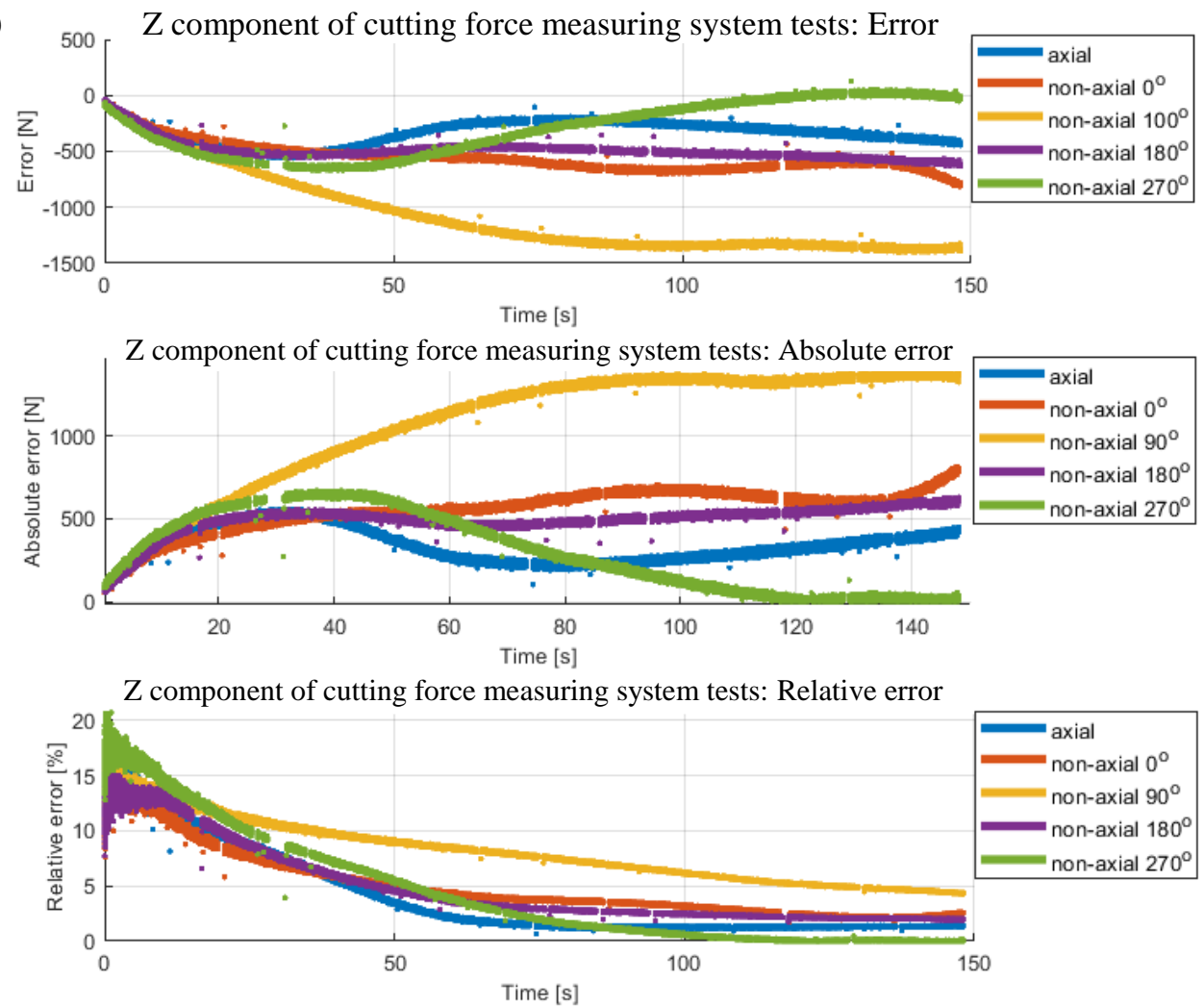

Fig. 14. Tests of $Z$ component of the cutting force transmission measuring system: a) reference value for force measurement, b) plots of measurement errors during and nonaxial compressive forces loading with axial

\section{CONCLUSIONS}

A solution for measuring machine tool steerable axes load has been presented. The main design assumption was the form of the measuring system enabling its full integration with the machine and operation in industrial conditions. This meant that the components used had to be in industrial versions and so, for example, able to operate in tough environmental conditions, have a hermetic housing, be replaceable and with proven performance. The presented solution was tested in laboratory conditions and met the above requirements. As part of this project, systems mapping the transmission of forces in the two steerable axes of the machine were built and tested.

The tests showed that the two systems transmit forces in a linear and repeatable manner under compressive load ranging from 0 to $30 \mathrm{kN}$. Moreover, the system for transmitting $\mathrm{Z}$ component of cutting force behaves in the same way in the case of tensile forces ranging from 0 to $30 \mathrm{kN}$. The incorporation of the designed systems into the machine does not require any significant structural modifications. The sensors used are strain gauges in their industrial versions. The systems successfully transmit nonaxial compressive forces whose deviation amounts to $4^{\circ}$.

The $X$ component of the cutting force measuring system is based on three sensors preloaded with the force of $10 \mathrm{kN}$. Under an axial load of up to $30 \mathrm{kN}$ the system is characterized by a discrepancy in force transmission relative to the reference value coming 
from the strength testing, amounting to $498 \mathrm{~N}$, and by a deflection of up to $14 \mu \mathrm{m}$. The system's deflection increases linearly with load, whereas the absolute measurement error has a linear character and reaches its maximum when the system is loaded with a force of about $10 \mathrm{kN}$. The relative error for $0-30 \mathrm{kN}$ force measurement on the average amounted to $3.78 \%$. The deflection which may cause the sliding connection to malfunction in the machine amounts to a small fraction of the connection's fabrication tolerance of 0-55 $\mu \mathrm{m}$. Therefore, it is assumed that the connection functions properly, which will be checked as part of the planned further research. Although the action of nonlinear forces has no significant influence on the force transmission error, it significantly increases the system's deflections. The absolute error for the measurement of forces deviating $4^{\circ}$ from the measuring system axis does not diverge from the one for the loading of the system with the axial force. The close error values and the parabolic shapes of the absolute error plots suggest that the measurement error stems from the nonlinear characteristic of the strain gauges. For the load of $30 \mathrm{kN}$ and its direction convergent with the system's compliance the deflection increases up to $42 \mu \mathrm{m}$. This value covers $76 \%$ of the tolerance range and can cause the connection to malfunction. However, it is a limit value and it is assumed that it will not occur in the machine. During the testing of this system a fault consisting in the loosening of the bolted connection was detected and rectified using a thread locking adhesive. Consequently, the error consisting in the failure of the signal to return to zero after the force decay was corrected.

Another solution presented in this paper is a system for measuring the force along the axis of the wheelset. The system is based on four sensors which carry compressive and tensile loads. The system's relative error for the axial load of $0-30 \mathrm{kN}$ on the average amounted to $1.02 \%$ for the compressive force and to $1.46 \%$ for the tensile force. The mean relative error in the above measuring range was significantly higher for the nonaxial load, amounting to $4.34-8.14 \%$ depending on the direction of loading force deviation from the measuring system axis. The direction of the system unloading force had a marked effect on the shape of the measurement error plots for the linearly increasing force and on the maximum and mean error values. Consequently, the strain gauge sensor nonlinear characteristic can be ruled out as the main source of the system error and one can assume that the measuring system structure is the main source of errors. While testing this system it was also noticed that the error increased with load (except for the nonlinear load deviating towards $270^{\circ} \mathrm{C}$ ). Hence it was concluded that the error was directly linked with the stiffness of the measured system and so with the elastic bending of its components. In order to reduce the force measurement error, it is proposed to increase the stiffness of the structural components or to modify the connections in the machine's force transmission chain [18].

Summing up, the two systems were built and checked regarding the transmission of the actual forces occurring during the operation of the machine tool. Considering that the systems show good operating performance, they can be successfully used to measure the loading of the machine tool's steerable feed axes. Future work will primarily include the integration of the feed axis load measurement system and the machine thermal condition monitoring system. Ultimately, it is planned to create comprehensive monitoring system for machine tool, that will enable the implementation of thermal and force-induced error reduction functions. 


\section{ACKNOWLEDGEMENT}

The authors express their thanks to NCBiR for supporting the research on intelligent machine tools, Project number POIR.04.01.04-00-0067/17.

\section{REFERENCES}

[1] ALTINTAS Y., ABELE E., BRECHER C., 2011, Machine Tools Spindle Units, CIRP Annals-Manufacturing Technology, 59, 781-802.

[2] CHEN J.S., CHEN K.W., 2005, Bearing Load Analysis and Control of a Motorized High Speed Spindle, International Journal of Machine Tools and Manufacture, 45, 12-13, 1487-1493.

[3] JEDRZEJEWSKI J., 1998, An Approach to Integrating Intelligent Diagnostics and Supervision of Machine Tools, Journal of Intelligent Manufacturing, 9/4, 295-302.

[4] JEDRZEJEWSKI J., 1985, Selected Diagnostic Methods for Machine Tools Acceptance Tests, CIRP Annals, 34/1, 343-346.

[5] BRECHER Ch., HIRSCH P., WECK M., 2004, Compensation of Thermo-Elastic Machine Tool Deformation Based on Control Internal Data, CIRP Annals, 53/1, 299-304.

[6] ROY R., 2016, Continuous Maintenance and the Future-Foundations and Technological Challenges, CIRP Annals, 65/2, 667-688.

[7] VERL A., FREY S., 2010, Correlation Between Feed Velocity and Preloading in Ball Screw Drives, CIRP Annals, 59/1, 429-432.

[8] JEDRZEJEWSKI J., 2019, Ball Screw Unit Precise Modelling with Dynamics of Loads and Moving Heat Sources Taken into Account, Journal of Machine Engineering, 19/4,27-41.

[9] JEMIELNIAK K., KOSMOL J., 1995, Tool and Process Monitoring - State of Art and Future Prospects, Scientific Papers of the Institute of Mechanical Engineering and Automation of the Technical University of Wroclaw, 61, 90-112.

[10] SKOCZYŃSKI W., STEMBALSKI M., ROSZKOWSKI A., JANKOWSKI T., TUREK P., PIÓRKOWSKI P., 2016, Sensors in the Contemporary CNC Machine Tools, Mechanik, 11/2016, 1740-1747, (in Polish).

[11] MĘDYK. P., JĘDRZEJEWSKI J., KASPRZAK M., 2019, CNC Machine Tool Error Compensation System Implementation Strategies and Their Constraints, Journal of Machine Engineering, 19/4, 70-81.

[12] MONOSTORI L., 2016, Cyber-Physical Systems in Manufacturing, CIRP Annals, 65/2, 621-641.

[13] FILIPOWICZ K., BIEDUNKIEWICZ W., KROLIKOWSKI M., GRZESIAK D., 2010, Machining of Resilient Wheelsets on Wheel-Turning Lathes, DAAAM International Scientific Book, Chapter 5, 41-48.

[14] STRYCZEK R., SZCZEPKA W., 2016, Process Factors of Impact on OEE for Lathes for Machining of Wheelset, Journal of Machine Engineering, 16/3, 126-140.

[15] YOU Z., YULONG Z., XIAOHUI G., 2018, The Development of a Triaxial Cutting Force Sensor Based on a MEMS Strain Gauge, Micromachines, 9/1, 30.

[16] KHOMENKO A., KORICHO E.G., MAHMOODUL H., ClOUD G., 2016, Bolt Tension Monitoring with Reusable Fibre Bragg-Grating Sensors, The Journal of Strain Analysis for Engineering Design, 51/2, 101-108.

[17] TETI R., JEMIELNIAK K., O’DONELL G., DORNFELD D., 2010, Advanced Monitoring of Machining Operations, CIRP Annals - Manufacturing Technology, 59, 717-739.

[18] FRIEDRICH C., KAUSCHINGER B., IHLENFELDT S., 2020, Stiffness Evaluation of a Hexapod Machine Tool with Integrated Force Sensors, Journal of Machine Engineering, 20/1, 58-69.

[19] INTERNATIONAL ORGANIZATION FOR STANDARIZATION, 1984, Basic Quantities in Cutting and Grinding - Part 4: Forces, Energy, Power, (ISO Standard No. 3002-4:1984). 